\title{
DESIGN AND TESTING OF A BACK-TO-BACK STARTING SYSTEM FOR PUMPED STORAGE HYDROGENERATORS AT MT. ELBERT POWERPLANT
}

by

Gary D. Osburn, Member, IEEE
Philip L. Atwater

\author{
U.S. Bureau of Reclamation \\ Denver Office \\ Denver, Colorado
}

\begin{abstract}
This paper describes the design and testing of a back-toback starting system for pumped storage hydrogenerators at Mt. Elbert Powerplant in central Colorado.

Marginal reliability of the existing static starting system adversely affected availability of the two 170,000 -hp pumps. An alternate method of starting a unit in the pump mode was needed to increase plant availability and to provide interim starting capability for a planned static starter replacement.

The U. S. Bureau of Reclamation research, design, maintenance, and operations forces worked together to design and test a back-to-back starting system that allows one unit, operating in generate mode, to synchronously start the other unit as a motor.

Field testing demonstrated the viability of back-to-back starting of the Mt. Elbert pumped storage units. A permanent back-to-back control system was designed and is in the process of being installed. Back-to-back starting will be used as a backup starting system for the present and future static starting systems and will be the only pump-starting method available during part of the static starting system replacement work scheduled for the spring of 1992.
\end{abstract}

\section{KEYWORDS}

Back-to-Back Starting, Hydro Plant, Pumped Storage, Static Starting, Synchronous Starting

91 SM 338-4 EC A paper recommended and approved by the IEEE Energy Development and Power Generation Committee of the IEEE Power Engineering Society for presentation at the IEEE/PES 1991 Summer Meeting, San Diego, California July 28 - August 1, 1991. Manuscript submitted February 1, 1991; made available for printing May 8, 1991.

\section{INTRODUCTION}

The Mt. Elbert Pumped Storage Powerplant, located approximately 100 miles southwest of Denver in central Colorado, was constructed in the 1970 s by the U.S. Bureau of Reclamation. The plant houses two 100-MW/170,000-hp, $11.5-\mathrm{kV}$ vertical, reversible pump-generating units that are used year round for peaking power. Due to limited forebay size, the units must be available for pumping on a regular basis so they can be used in the generator mode.

At the recommendation of the generator contractor, Reclamation decided to install a static starting system, capable of synchronously starting either unit. By the mid 1980s, both pump-generators were available for commercial service.

From the beginning, the static starting system proved unreliable in starting a unit. Problems included intermittent failure of the control logic and recurring failure of power components. The control logic design was of the analog type. Among other problems, the electronic circuits were susceptible to electromagnetically induced noise and, quite often failed to operate due to controlled voltage references that drifted. The major problem associated with this starting system is that it was a prototype and was never advanced beyond that point. Over time, replacement parts became difficult to obtain. Eventually unit reliability deteriorated to the point that unit commitment schedules for both generation and pumping suffered.

As a result of these problems, a decision was made to replace the existing static starting system with a new one that would benefit from mature state-of-the-art technology, including microprocessor logic for the controls. To further enhance unit reliability, it was decided that tests for back-to-back starting capability would be conducted and, if successful, a permanent back-to-back control system would be installed. This back-toback capability would provide a "backup" mode of starting one unit in the event of failure of the existing starting system and would also provide interim starting capability during replacement of the existing static starter.

Synchronous back-to-back starting is a proven reliable method of starting pump-generating units [1], [2], [3], [4]. This method is also known as full synchronous starting since both 


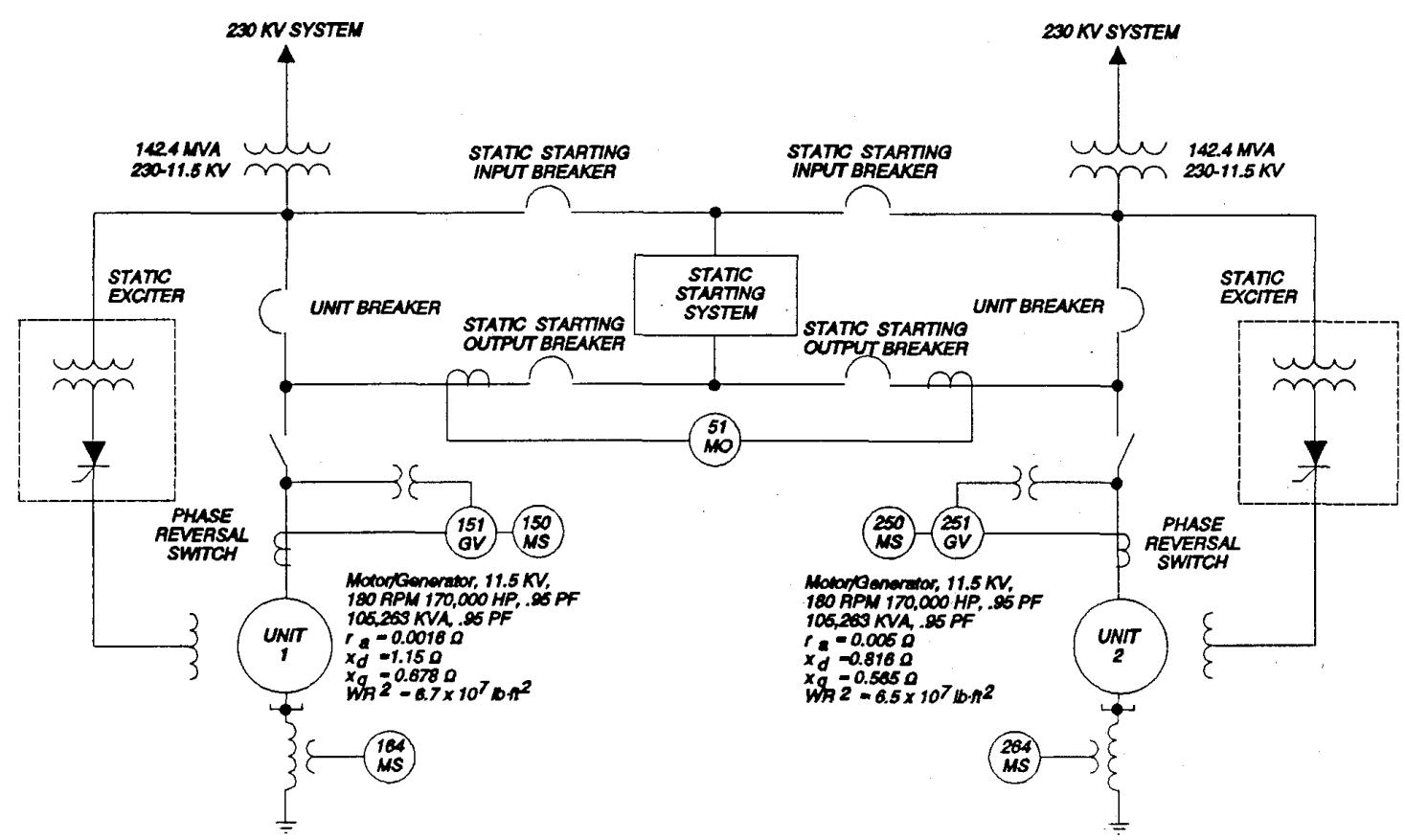

Figure 1

Mt. Elbert Powerplant

Abbreviated Single-Line Diagram

units stay in synchronism during the entire starting process [3], [4]. To start a unit in this mode, the water is typically depressed below the pump impeller and the rotor field is applied to both machines. With brakes released on both units and the stator windings electrically connected (back-to-back), the generator is accelerated from dead stop to rated speed at a controlled rate. As the generator starts to rotate, the motor breaks away from a dead stop and pulls into synchronism with the generator during the first half electrical cycle. At rated speed, motor terminal voltage is matched to system voltage by adjusting excitation on both units. Motor frequency is controlled by adjusting generator speed. When the motor-to-system voltage, speed, and phase angle are correct, the motor is separated from the generator and is then connected to the power system through the unit circuit breaker.

Back-to-back starting requires the availability of a generating unit to start the pump-motor unit. It also requires that both units be excited during the start to maintain synchronism. Therefore, the units must be separately excited or have excitation power furnished from the system side of the unit circuit breaker [1],[4]. In addition, back-to-back starting requires a fairly involved operating procedure and experienced operators to successfully make such a start. At Mt. Elbert, the availability of a generating unit is assumed, and limited only by maintenance outages. Both units are excited through static excitation systems connected to the system side of the unit breakers. Since back-to-back starting is a backup mode of starting at this plant, only experienced operators will. be called upon to conduct such a start.

For these reasons, back-to-back starting was researched and on-site testing was successfully conducted. Knowledge gained from these tests was useful in designing a permanent back-to-back control system.

\section{$\underline{\text { PLANT CONFIGURATION }}$}

Mt. Elbert powerplant is used to provide peaking power daily. The plant is currently staffed full time by operators. A centralized, local-manual control system allows operation from the 10th floor control room; the static starting system, including input and output switchgear, is located on the 4th floor. One or both units typically generate power during twiceper-day peak demand periods. At night, when system demands are low, one or both units pump water into the forebay for the next day generation cycle. Being able to pump water on a regular basis is very important because the forebay is small relative to generation needs. In addition, inflow to the forebay is very limited. Therefore, a reliable pump-starting method is critical. 
282

An abbreviated plant single-line diagram is illustrated in Figure 1. When starting a unit with the static starting system, the starting system input and output breakers associated with that unit are closed and the unit is "ramped up" in speed and voltage by the starter. During synchronizing, the input and output breakers are opened and the unit breaker is closed. This entire automatic process is controlled by the static starter. For manual back-to-back starting, both starting system output breakers are closed to electrically connect the generator and motor stators. Prior to this, the static starter and input breakers are disabled.

The protective relaying in Figure 1 is the only plant relaying significant to this discussion. Briefly, this protection includes:

- Motor-starting system overcurrent relay 51MO detects faults in the motor-to-starter connection during a start.

- Unit stator voltage restrained overcurrent relays $151 \mathrm{GV}$ and $251 \mathrm{GV}$ detect power system frequency faults in buswork connected to the machine terminals.

- Motor-starting subsynchronous overcurrent relays $150 \mathrm{MS}$ and 250MS detect faults at frequencies less than $60 \mathrm{~Hz}$ in machine stator windings or buswork connected to the machine terminals.

- Motor-starting subsynchronous stator ground relays $164 \mathrm{MS}$ and $264 \mathrm{MS}$ detect ground faults at frequencies less than $60 \mathrm{~Hz}$

As will be seen in later discussion, it is necessary to either disable or reconnect these relays to protect the machines and switchgear during back-to-back starting.

\section{TEST THEORY}

The existing static starter system is basically a 3-phase load commutated frequency converter consisting of a directcurrent rectifier/inverter link. The current rating of the link limits motor/turbine acceleration during pump start up. The starting system requires approximately 4 minutes to accelerate a unit from standstill to synchronous speed. The switchgear and bus used for back-to-back starting have a 50\% higher current rating than the static starter power components. Therefore, based on these limitations, a shorter starting time was desired in the back-to-back mode.

Studies were conducted to determine the available synchronous power transfer between generator and pump connected back-to-back and the unwatered pump load at any speed ( 0.1 to $60 \mathrm{hertz}$ ). Synchronous power in excess of the pump load can be used to accelerate the pump and determines the acceleration time to synchronous speed. Classical salient pole $d-q$ axis equations for the real and reactive power transfer between machines were applied as follows:

$$
\begin{aligned}
P & =\frac{3 E_{g} E_{m}}{I_{a}^{2}+x_{d} x_{q}}\left(x_{q} \sin \delta-r_{a} \cos \delta\right) \\
& +\frac{3 E_{g}^{2}}{I_{a}^{2}+x_{d} x_{q}}\left[I_{a}+\left(\frac{x_{d}-x_{q}}{2}\right) \sin 2 \delta\right] \\
\ell & =\frac{3 E_{q}^{2}}{I_{a}^{2}+x_{d} x_{q}}\left(x_{q} \cos ^{2} \delta+x_{d} \sin ^{2} \delta\right) \\
& -\frac{3 E_{g} E_{m}}{I_{a}^{2}+x_{d} x_{q}}\left(I_{a} \sin \delta+x_{q} \cos \delta\right)
\end{aligned}
$$

where the positive sign convention for power flow is from generator to motor; and

$\mathrm{P}=3$-phase real power (watts)

$\mathrm{Q}=3$-phase reactive power (vars)

$\mathrm{E}_{\mathrm{g}}=$ generator air gap voltage $(\mathrm{Vp}-\mathrm{n})$

$\mathrm{E}_{\mathrm{m}}^{\mathrm{g}}=$ motor air gap voltage $(\mathrm{Vp}-\mathrm{n})$

$x_{d}=$ generator + motor direct axis reactance (ohms)

$x_{\mathrm{q}}=$ generator + motor quadrature axis reactance (ohms)

$r_{\mathrm{a}}=$ generator + motor stator winding d.c. resistance (ohms)

$8=$ generator to motor rotor torque angle (degrees)

All reactances and machine stator winding resistances were treated as frequency-dependent variables in order to accurately determine power transfer from rated frequency (speed) to almost standstill ( 0.1 -hertzoperation). The frequency-dependent stator winding resistance is due to skin and proximity effects in the slots. These effects were later determined to be negligible, but were included in all calculations for completeness. However, the direct-current resistance of the stator windings is not negligible, especially at low speeds where the magnitude of inductive reactance is less than the winding resistance.

Calculated real and reactive power transfer curves for backto-back connected machines at Mt. Elbert are illustrated in Figure 2. The family of curves are for machine speeds ranging from 0.1 to 60 hertz. Rotor current (flux) of both machines was assumed constant at a magnitude that would produce rated terminal voltage at speed no-load. A decrease in the stator winding resistance causes the peak of the real power curve to flatten and move toward a rotor torque angle of $90^{\circ}$ at low frequency (less than 1 hertz). Additional equations were derived to plot stator phase current as a function of torque angle and speed and are shown by the family of curves of Figure 3. As can be seen, a limited amount of synchronous power is still available at frequencies as low as 0.1 hertz at a torque angle representing 1200-A phase current (switchgear rating). 

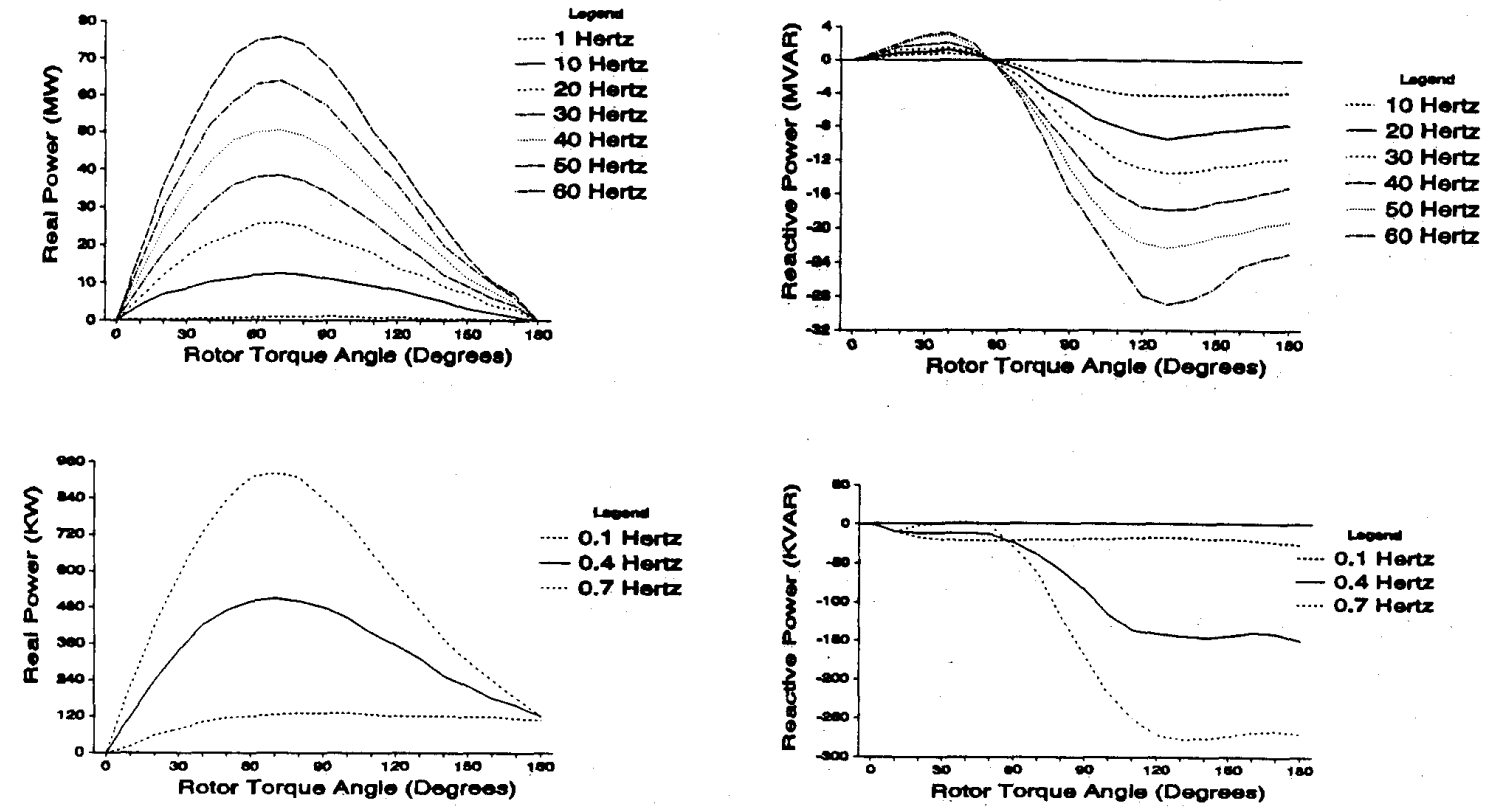

Figure 2

Calculated Synchronous Power Transfer

Between Back-to-Back Connected Generator and Pump

Pump motor load at the machine terminals must be estimated throughout the speed range to determine if acceleration power is available. This is critical at very low speeds due to limited synchronous torque. Measured losses for pump impeller drag (unwatered), motor windage and friction, and stator core magnetization at synchronous speed

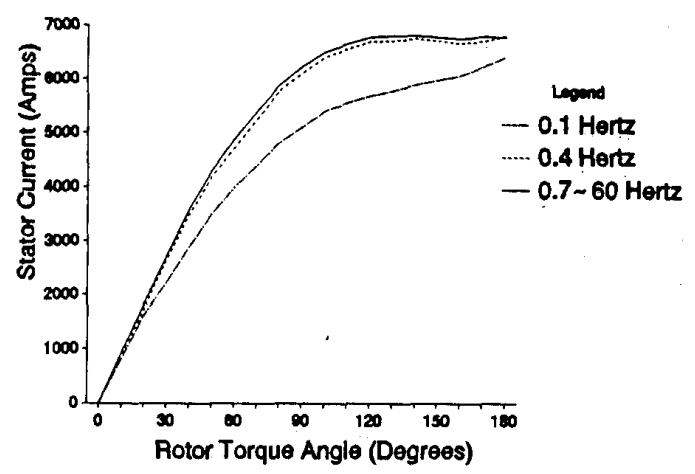

Figure 3

Calculated Generator and Pump Motor Phase Current vs. Rotor Torque Angle with Constant Field Current Applied were approximated as speed-dependent variables and totalized (Figure 4). The difference in synchronous electric power minus the pump loss power could then be integrated with speed to determine acceleration time as follows:

$$
t=k \int_{0.1}^{f} \frac{f}{P(f)-P_{1}(f)} d f
$$

where

$t=$ time in seconds to unit speed $\mathrm{f}$ in hertz

$P(f)=$ synchronous power as a function of frequency $P_{1}(f)=$ pump loss power as a function of frequency

$\mathrm{k}=$ constant accounting for machine $\mathrm{WR}^{2}$, hertz vs. rpm, etc.

A calculated speed curve for a Unit 1 pump start is illustrated in Figure 5. This curve is based on a constant 1200-A phase current $\left(12^{\circ}\right.$ rotor torque angle) and requires the operator to adjust the generator wicket gates to maintain the torque angle while the units accelerate. In practice, adjustment of the wicket gates was easier than anticipated and phase current was easily controlled once the units accelerated past $10 \%$ speed. 
to determine synchronous operation. As a precaution, the generator was started at several trial gate openings of less than $10 \%$ to promote rapid rotor pull-in with the pump and thereby minimize the possibility of an out-of-step startup. For comparison, these turbines require approximately $20 \%$ gate opening for speed no-load operation.

Strip chart recorder records for a Unit 1 pump start are depicted in Figure 6 and are typical of all test starts for either pump. Prior to starting, the rotor currents of both machines were preset to levels that would produce $11.5 \mathrm{kV}$ terminal voltage at synchronous speed, no-load. The generator wicket gate limit was then raised to $5 \%$. Generator rotor breakaway is evident from the oscillations in phase and rotor currents at the beginning of the records. These oscillations quickly damped out, indicating the generator and motor rotors immediately pulled into step and oscillated relative to one another for only a few seconds (less than 10 electrical cycles). Once the machines accelerated to $10 \%$ speed, the operator could easily increase the generator gate opening in two or three increments to maintain approximately 1200 -A phase current and thereby minimize acceleration time. An exchange of reactive power between units was minimal (unity power factor operation) as can be seen from the var curves in Figure 2. Acceleration time to synchronous speed was 80 seconds.

The results of the model studies indicated that either pump could be synchronously started back-to-back in slightly under 1 minute. Field tests were conducted to confirm the starting characteristics of the machines in this configuration and to determine pertinent starting operation procedure.

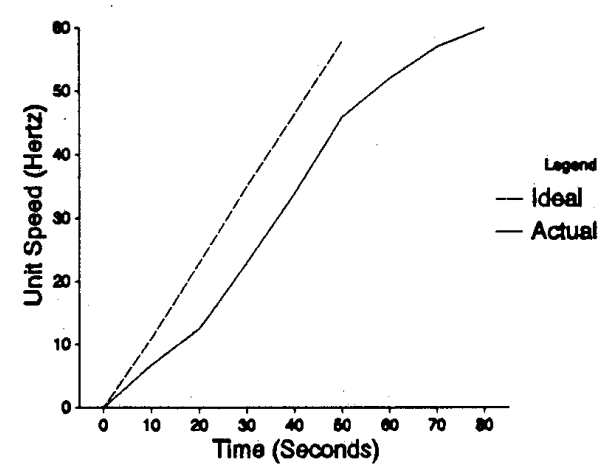

Figure 5

Ideal vs. Actual Speed Curve for Back-to-Back Unit 1 Pump Start at 1200 Amp Phase Current

Instrumentation was installed to monitor stator and rotor currents and terminal voltage. Of major concern was how well the motor would break away from a dead stop and pull into step immediately following the opening of the generator wicket gates. Rotor and phase current information was used
Gate openings for breakaway were increased in an effort to determine if prolonged rotor swings or slipping would represent a control problem for the operator. Rotor pull-in was found to be immediate for gate openings substantially larger than necessary for moderate stator phase current swings and adequate acceleration. Therefore, the operator had an adequate margin of wicket gate control.

At rated speed, the generator/pump combination was manually synchronized to the power system using a synchroscope. Unit speed and phase angle were adjusted with the generator governor speed control. Machine field currents were adjusted to match terminal voltage with the system while maintaining essentially zero var flow between machines. Synchronizing was completed by tripping both static starting output breakers to separate the machines and then closing the pump unit breaker (Figure 1). The breaker controls were interlocked so the pump unit breaker would automatically close after the tie breakers opened.

Due to the unconventional connection of generator to pump, several existing protective relaying schemes had to be either disabled or modified to accommodate back-to-back starting. Overcurrent relays (51GV and 51MO) intended for operation at 60 hertz were disabled. Overcurrent protection for the entire system (machines, switchgear, and bus) was provided by subsynchronous phase and ground overcurrent relays $50 \mathrm{MS}$ and $64 \mathrm{MS}$. The static starter output breakers have no interrupting rating at low frequency. Therefore in 

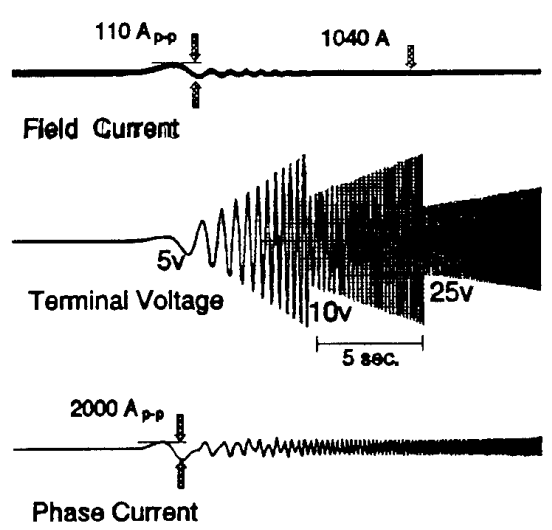

Figure 6

Plant Test Current and Voltage Records for Back-to-Back Unit 1 Pump Start

the event of a fault, the 50MS and 64MS relays were connected to first phase back the static exciters and demagnetize the machines before tripping the circuit breakers. Unit current differential relaying (not shown) remained in service and was reconfigured to trip and shut down both machines.

\section{PERMANENT INSTALLATION}

After completion of the testing that proved the feasibility of starting the units in back-to-back mode, designs were finalized for installation of a permanent back-to-back control system. The control system, used in conjunction with a special operating procedure, allows the operator to manually start either pump unit in the back-to-back mode quickly and easily. Since it is anticipated that back-to-back starting at Mt. Elbert will be a rare event, a decision was made to specify a semiautomatic starting system rather than an expensive fully automatic system.

The control room, usually staffed with one operator, is located several floors above the starting equipment and the plant. Therefore, an important design parameter was to reduce the number of control actions required by the operator and to minimize the distance the operator had to travel to accomplish them. The back-to-back starting procedure selected requires the operator to take action on remote floors initially to prepare for a start; following that, all other control actions are performed in the control room.

A back-to-back control panel was designed to house the associated control, indication, and protection devices in the control room. These comprise the following:
- Control switch for back-to-back "Enable" and "Disable" selection.

- Emergency shutdown control switch for operator abort of the back-to-back starting sequence.

- Starting system breaker control switch to close the circuit breakers that electrically connect the generator and motor stators.

- Shutdown and lockout relay for back-to-back mode emergency protective actions.

- Indicating lights to show: Back-to-back "Enabled" or "Disabled", Starting System circuit breakers "Open" or "Closed", and lockout relay "Reset and Ready" or "Tripped."

Generator and motor protective relaying must be temporarily reconfigured for back-to-back starting, similar to the changes made for the tests. After the start is successful (pump synchronized to the line), the protective relaying must easily be returned to normal protective status. These protection modifications include:

- Motor-starting time-delay overcurrent relay 51MO must be disabled.

- Unit phase overcurrent (voltage restrained) relays $151 \mathrm{GV}$ and $251 \mathrm{GV}$ must be disabled.

- Motor-starting overcurrent relays 150MS and 250MS and motor-starting ground detection relays $164 \mathrm{MS}$ and 264MS must be reconfigured to phase back excitation on the units prior to tripping lockout relays.

Where relays are completely disabled, the trip output is simply disconnected by opening the test switches on the relay case. Where relays need to be temporarily reconfigured, this is accomplished by using current and voltage type test switches that are manually opened or closed by the operator during the starting procedure. This action was considered more secure than using control switch and auxiliary relay contacts that operate in response to the "Enable" and "Disable" mode selected by the back-to-back control transfer switch.

A condensed version of the back-to-back standard operating procedure follows:

- Check unit circuit breakers open and all plant conditions normal for unit start.

- Check starting system circuit breakers open.

- Enable back-to-back start control system. 
- Operate phase reversal switches to "Motor" and "Generator" positions as appropriate.

- Disable and reconfigure affected protective relays.

- Start unit auxiliaries and depress water below the pump impeller.

- Close starting system breakers to electrically connect the machine stators.

- Apply the field to both machines.

- Release brakes on both machines.

- Accelerate the generator to $100 \%$ speed; the motor will follow.

- Adjust the speed, phase angle, and voltage magnitude to synchronize the motor with the power system. Close the motor unit circuit breaker. This automatically opens motor-starting breakers.

- Release the water onto the pump impeller.

- Shut down the generator. Disable back-to-back starting control. Return protective relaying to normal state.

During back-to-back starting, the operator must watch electrical quantities carefully and react accordingly to reduce risk to the equipment:

- At breakaway, sustained fluctuations in dc field current and/or ac phase current indicate the units are running out of step. The generator must be slowed to allow the motor to pull into step.

- Above $10 \%$ of rated speed, phase current sufficient to transfer accelerating power to the motor must be maintained. Current is manually controlled by operator adjustment of generator turbine wicket gates.

- As the units approach $100 \%$ speed, terminal voltage must not exceed speed-no-load voltage.

\section{CONCLUSIONS}

Design, testing and installation of a back-to-back starting system for the pumped-storage hydrogenerators at Mt. Elbert was necessary to increase the availability of these units.

A theoretical analysis of the feasibility of such starting showed the machines and plant systems to be capable of backto-back starting. Critical electrical and mechanical variables, such as synchronous power transfer capability and generator wicket gate control, were believed to be well within safe limits for starting either unit in this fashion. Special considerations were given to the fault current limitations of the motor-starting switchgear and buswork. Control and protective relaying schemes were studied and modified where necessary to accommodate the unusual back-to-back starting conditions and provide adequate equipment protection.

On-site testing took place during January 1990 with temporary control and protection modifications in place. Numerous types of data were recorded for analysis. As normal in any field prototype investigation, numerous problems were encountered and resolved. Several test runs took place to demonstrate that each unit could start the other in back-to-back configuration.

After testing, final designs for permanent installation were completed. Standard operating procedures were refined and final installation control equipment specified. Permanent installation should be completed by late 1991. Back-to-back starting will be used when the static starting system is replaced and whenever the starting system is down for maintenance.

\section{REFERENCES}

[1] Hammons, T.J. and Loughran, J.; "Starting Methods For Generator/Motor Units Employed In Pumped-Storage Stations"; Proceedings of IEE, Vol. 117, No. 9, September 1970.

[2] Petersson, Tore; "Starting Methods For Reversible Pumped-Storage Generator/Motors"; ASEA Journal 1973, Volume 46, Number 6.

[3] Bose, B., Canay, M., Simond, J.-J.; "Frequency Starting In Pumped Storage Plants: Possibilities and Optimization"; Brown Boveri Review, Vol. 70, No. 7-8, pp. 295-302, JulyAugust, 1983.

[4] Canay, M.; "Partial Frequency Starting In Pumped Storage Stations"; Brown Boveri Review, Vol. 61, No. 7, pp. 319326, July 1974.

\section{BIOGRAPHIES}

Gary D. Osburn was born in Colorado Springs, Colorado on April 5, 1949 and received his BSEE from Colorado State University in 1971. Mr. Osburn began his career with the U.S. Bureau of Reclamation in 1976 and has worked in the design, construction, and testing of various Reclamation hydroelectric powerplant control systems. $\mathrm{He}$ is a member of the IEEE Power Engineering Society and has served on several working groups preparing guides on hydro plant control, rehabilitation, and automation. Mr. Osburn is a registered professional 
engineer in the state of Colorado and is presently a supervisor in the Plant Control section at Reclamation design offices in Denver, Colorado.

Philip L. Atwater was born in the state of Michigan on January 18,1953 . He received a B.S. degree in electrical engineering from Michigan State University in 1975 before moving to Colorado. $\mathrm{He}$ is a registered professional engineer in the state of Colorado.

In 1975, he joined the U.S. Bureau of Reclamation as an electrical engineer in the Electrical Branch, Division of Design. In 1984 he transferred to the Electric Power Branch, Division of Research and Laboratory Services, where he is currently the section head of the Power Apparatus and Systems Section. He has performed design, research, and/or field testing in the areas of powerplant control and protective relaying, personal protective grounding, power system staged fault testing and special instrumentation, and power system harmonics. 


\section{Discussion}

J. T. Madill: It was most interesting to read the paper on "Back-To-Back Starting" by Osburn and Atwater. This recalled memories of 1946/47 when immediately after World War II in Canada power equipment was obtainable only with a very long delay, about two years. The Aluminum Company of Canada had a smelter at Shawinigan Quebec, as well as in the Saguenay Region. Power was available in the latter area and arrangements could be made with the then Shawinigan Water and Power Co. to transmit the energy to Shawinigan, some average of $180 \mathrm{Mw}$ about 300 miles, but of course the reactive requirements of the smelter had to be supplied locally.

Since capacitors could not be obtained promptly it was decided to move a 50 Mva hydro generator from the Chute a Caron powerplant in the Saguenay and set it up in a field beside the smelter as a snychronous condenser. The only question was how to start it up and synchronize it with the system. This $50 \mathrm{Mva}$ generator was to come from a hydro station in the Saguenay River operating hydraulicly in parallel with the newly constructed Shipshaw plant which had a considerably higher head and could normally use all the water in the Saguency River.

To test the start-up procedure for the synchronous condenser three of four $50 \mathrm{Mva}$ units were made available at the Chute a Caron plant. One was to provide excitation to the other two from its main exciter, a second was to be the driving unit and the third the machine to be started. The latter two were connected through $57 \mathrm{Mva} 13.2 / 161 \mathrm{Kv}$ transformer banks and two 4 mile $161 \mathrm{Kv}$ transmission lines to an isolated section of $161 \mathrm{Kv}$ bus at the Arvida smelter. The turbines were Francis type, but with only one of four units operating, the runner of the unit being started was clear of the tailrace water.

On the first trial, everything was connected together electrically and about $120 \%$ of normal speed no-load field was applied. When the wicket gates were opened slowly, at about $50 \%$ above normal starting gate position both units began to rotate and were brought up to normal speed with no difficulty. Subsequent tests showed that field current equal to normal speed no-load field was also satisfactory, but with lower field the driven unit would not commence rotation. On a normal start generator stator current did not exceed normal full load current.

When the 50 Mva generator was erected in the smelter yard, with a separate motor-generator unit for excitation it was started using a short transmission line to one $30 \mathrm{Mva}$ unit of a near-by power station of the Shawinigan Water and Power Co. At normal speed the generator was synchronized, the synchronous condenser was connected to the potline 13.2 $\mathrm{Kv}$ bus, and the transmission line and generator returned to normal operation. Obviously the synchronous condenser was stopped only on rare occasions.

This arrangement existed for several years, supplying 50 Mvar at the potline bus, until the generator was required back in the power station for peaking and for maintenance replacement capacity, and until static capacitors could be obtained and installed.

Back-to-back starting certainly proved its worth in this case.

Manuscript received July 30, 1991.

G. D. Osburn and Phillip L. Atwater: The authors thank Mr. Madill for sharing his experience with synchronous back-to-back starting of a 50 MVA synchronous condenser for smelting operations. Mr. Madill's application, along with others who have used this technique over the years, further demonstrates the elegance this scheme offers for starting large synchronous machines. Based on our experience at Mt. Elbert and another hydroelectric power plant, the method has proven very effective and requires minimal technical study to determine feasibility for typical applications. Much of the effort devoted to the Mt. Elbert study described in this paper was expended to satisfy the authors' needs to predict the starting time and guide the plant operators through the first test starts.

Manuscript received November 4, 1991 